\title{
AURKC Gene Polymorphism (rs58264281) Associated with Idiopathic Male Infertility Risk in Northeast of Iran: A Case-Control Study
}

\author{
Mohammadreza Behvarz ${ }^{1}$, Seyyed Ali Rahmani ${ }^{2,}{ }^{,}$, Elham Siasi Torbati ${ }^{1}$, Shahla Danaei Mehrabad ${ }^{3}$ \\ and Maryam Bikhof Torbati ${ }^{4}$ \\ ${ }^{1}$ Department of Genetics, Faculty of Biological Sciences, North Tehran Branch, Islamic Azad University, Tehran, Iran \\ ${ }^{2}$ Department of Medical Genetics, School of Medicine, Tabriz University of Medical Sciences, Tabriz, Iran \\ ${ }^{3}$ Department of Gynecology, Eastern Azerbaijan ACECR ART Center, Eastern Azerbaijan Branch of ACECR, Tabriz, Iran \\ ${ }^{4}$ Department of Biology, Yadegar-e-Imam Khomeini (RAH) Shahr-e-Rey Branch, Islamic Azad University, Tehran, Iran \\ "Corresponding author: Department of Medical Genetics, School of Medicine, Tabriz University of Medical Sciences, Tabriz, Iran. Email: rahmaniseyedali@yahoo.com
}

Received 2021 September 17; Revised 2021 October 31; Accepted 2021 November 02.

\begin{abstract}
Background: Infertility is a major public health and social problem in human reproduction that is known as a multifactorial complex disorder. Genetic background and mutations and single nucleotide polymorphisms (SNPs) on the genes involved in sperm development are the important causes of male infertility.

Objectives: In this study, we evaluated the association of AURKC gene polymorphism (rs58264281) and idiopathic male infertility in the Iranian Azeri population.

Methods: This study was performed among 100 men with idiopathic infertility (case group) and 100 healthy men with successful fertility (control group) from East Azerbaijan, Iran. Genomic DNA extraction was carried out from peripheral blood samples by the proteinase K method. Genotype analysis was conducted by the tetra-primer amplification refractory mutation system-polymerase chain reaction (Tetra-ARMS PCR). SPSS version 21 was used for the analysis of the obtained data.

Results: We observed that the CA and AA genotypes were significantly increased in patients with infertility as compared to healthy controls. Our results demonstrated that the mutant allele of AURKC gene polymorphism (rs58264281) was a significant risk factor in male infertility.

Conclusions: We suggested a significant correlation between the AURKC gene rs58264281 polymorphism and male infertility in the Iranian Azeri population. However, further studies are required among other ethnicities, races, and geographic areas with larger sample sizes.
\end{abstract}

Keywords: Male Infertility, AURKC, Polymorphism, Tetra-ARMS PCR

\section{Background}

Infertility is a critical reproduction problem with social consequences. Male infertility factors include a high proportion of all infertility cases that may be observed along with female infertility factors or alone $(1,2)$. Male infertility is a complex problem that can occur due to environmental and genetic/epigenetic factors $(3,4)$. Idiopathic male infertility includes approximately $40 \%$ of all male infertility cases that may be associated with genetic and genomic factors $(5,6)$. In recent years, several single nucleotide polymorphisms (SNPs) in the genes involved in sperm development have been identified that can increase the risk of male infertility $(7,8)$.

The AURKC gene is a major cause of monomorphic teratozoospermia (macrozoospermia), which is known as macrocephalic multiflagellar spermatozoa syndrome (9). This disorder is commonly associated with oligozoospermia and characterized by large-headed and multiflagellar spermatozoa (6). The AURKC gene encodes the third member of the Aurora subfamily of serine/threonine protein kinases and is commonly expressed in the testis. Evidence suggests that the AURKC protein plays an essential role in the production of euploid gametes through the control of microtubule-kinetochore attachment and verifying the bi-orientation of tensions preceding chromosome segregation $(10,11)$. Moreover, the AURKC protein participates in the spindle assembly checkpoint (SAC) that inhibits the production of aneuploid cells in mitosis and incorrect microtubule segregation in meiosis, which reduces chromosomally abnormal gametes $(12,13)$. Previous studies have reported that several mutations and SNPs in the AURKC 
gene cause defects in the function of encoded proteins, which are associated with male infertility $(14,15)$.

\section{Objectives}

So far, numerous studies have investigated the association of the AURKA gene polymorphisms and male infertility in various populations. However, the reported results by these studies are very inconsistent. This is the first attempt to evaluate the association of the AURKC gene polymorphism (rs58264281) and idiopathic male infertility in the Iranian Azeri population.

\section{Methods}

\subsection{Study Subjects}

This case-control study was conducted among 100 infertile men ( 25 - 50 years old) with idiopathic azoospermia and oligospermia as the case group and 100 healthy men (age and ethnic matched and genetically unrelated) with previous successful reproduction as the control group. The participants were from Azerbaijan, Iran, and were referred to the Department of Infertility, Valiasr Hospital, Tabriz, Iran. In the case group, the patients with cryptorchidism, hypogonadotropic, hypogonadism, orchitis, ejaculatory duct obstruction, microdeletions on Y chromosome, and abnormal karyotype were excluded from the study. We recorded the demographic characteristics of all the patients and healthy controls by questionnaires and interviews (Table 1). All the patients and healthy controls were first informed of the study objectives and then signed a consent form. The present study was approved by the Ethics Committee of Islamic Azad University, North Tehran Branch, Tehran, Iran (code of ethics: IR.IAU.TNB.REC.1399.030).

\subsection{Genotype Analyses}

Genomic DNA extraction was carried out using 5mLwhole blood samples by the proteinase K method. The quality of the extracted genomic DNA samples was investigated using electrophoresis on $1 \%$ agarose gel. In addition, the quantity of the extracted genomic DNA samples was investigated using a nanodrop instrument. The genotype analyses of the DNA samples were carried out using the tetra-primer amplification refractory mutation system-polymerase chain reaction (Tetra-ARMS PCR) method. The designed primers included: (1) forward outer in: $5^{\prime}$-GGTGTATGCGTTGTTCATTCCCACA-3'; ${ }^{\prime}$ (2) reverse outer in: $5^{\prime}$-TCCTGAACCCTCTGGATGGCTGTT- $3^{\prime}$; (3) forward inner: $5^{\prime}$-GTAGCAGTGAGACATCAGTGAGGC-3'; (4) reverse inner: $5^{\prime}$-CGCTTCCAATCCTGCTCGTCCTGTAA-3'. The amplification was conducted using a 50-ng template DNA $(1 \mu \mathrm{L})$,
$250 \mathrm{nM}$ each primer $(0.5 \mu \mathrm{L})$, and $1 \mathrm{X}$ Master Mix $(12.5 \mu \mathrm{L})$ in a total volume of $25 \mu \mathrm{L}$. Condition: 1 cycle for the initial denaturation ( 5 minutes in $94^{\circ} \mathrm{C}$ ), 30 cycles for denaturation ( 40 seconds in $94^{\circ} \mathrm{C}$ ), annealing ( 45 seconds in $60^{\circ} \mathrm{C}$ ), and extension ( 45 seconds in $72^{\circ} \mathrm{C}$ ), and 1 cycle for the final extension ( 5 minutes in $72^{\circ} \mathrm{C}$ ). The amplified PCR products were separated using electrophorese on $2 \%$ agarose gel, and the sizes of the fragments were estimated by a 50bp ladder (122 bp for allele C and 366 bp for allele T).

\subsection{Statistical Analysis}

The obtained data were analyzed by SPSS, version 21.0. The demographic characteristics of the case and control groups were analyzed by independent samples t-test. Hardy-Weinberg equilibrium (HWE) was investigated by the chi-square $\left(\chi^{2}\right)$ test and Fisher's exact test. The correlation of the AURKC gene rs58264281 polymorphism and male infertility risk was investigated by logistic regression. A P-value of less than 0.05 was considered significant.

\section{Results}

\subsection{Demographic Characteristics}

The demographic characteristics of the patients and healthy controls are demonstrated in Table1. The statistical analysis demonstrated that positive family history of infertility and tobacco smoking in the control group was significantly less than the case group $(\mathrm{P}<0.05)$, suggesting that positive family history of infertility and tobacco smoking are significant genetic and environmental factors increasing the risk of infertility in Iranian Azeri men. Moreover, we observed that the concentration, motility, and volume of sperm in the control group were significantly higher than in the case group $(\mathrm{P}<0.05)$. However, the statistical analyses indicated no significant differences between the case and control groups in terms of age, body mass index (BMI), and alcohol consumption ( $\mathrm{P}>0.05)$.

\subsection{Genotype and Allele Distribution}

The genotypic distribution of the AURKC gene rs58264281 polymorphism in the case and control groups was in agreement with HWE $(\mathrm{P}>0.05)$. The obtained results demonstrated that the risk of male infertility was significantly increased in the presence of CA ( $\mathrm{P}=$ 0.0046; OR = 7.08; 95\% CI: 1.7 - 32.2) and AA (P = 0.022; OR = infinity; 95\% CI: 1.7-infinity) genotypes. Moreover, our results demonstrated that the presence of A mutant allele $(\mathrm{P}=0.0001 ; \mathrm{OR}=12.2 ; 95 \% \mathrm{CI}: 3.2$ - 53.1) significantly increased the risk of male infertility (Table 2 ). These results suggest a significant association between the AURKC gene rs58264281 polymorphism and male infertility in the 


\begin{tabular}{|c|c|c|c|}
\hline Variables & Patients $(n=100)$ & $\operatorname{Controls}(n=100)$ & P-Value \\
\hline Age $(y)$ & $29.33 \pm 2.78$ & $27.6 \pm 3.06$ & 0.298 \\
\hline BMI $(\mathbf{k g} / \mathbf{m})$ & $26.25 \pm 2.18$ & $26.48 \pm 2.34$ & 0.699 \\
\hline \multicolumn{4}{|l|}{ Tobacco smoking } \\
\hline Never & $76(76)$ & $89(89)$ & - \\
\hline Ever & $34(34)$ & $11(11)$ & $0.004^{\mathrm{b}}$ \\
\hline \multicolumn{4}{|l|}{ Alcohol consumption } \\
\hline Never & $39(39)$ & $31(31)$ & - \\
\hline Ever & $61(61)$ & $69(69)$ & 0.376 \\
\hline \multicolumn{4}{|l|}{ Family history } \\
\hline Negative & $79(79)$ & $100(100)$ & - \\
\hline Positive & $21(21)$ & $0(0)$ & $0.008^{\mathrm{b}}$ \\
\hline \multicolumn{4}{|l|}{ Semen parameters } \\
\hline Concentration $\left(\times 10^{6} / \mathrm{mL}\right)$ & Median: 3.5 (0 - 6.37); Mean: $3.71 \pm 3.94$ & $125.5(94-156.3) ; 126 \pm 40.3$ & $<0.0001^{\mathrm{b}}$ \\
\hline Motility() & $\begin{array}{c}\text { Median: } 48.5(0-63) ; \text { Mean: } 33.95 \pm \\
30.48\end{array}$ & $60(49-70) ; 59.6 \pm 11.55$ & $<0.0001^{\mathrm{b}}$ \\
\hline Volume (mL) & Median: 3.5 (2.35 - 4); Mean: $3.23 \pm 1$ & $4(3-5) ; 4.18 \pm 3.19$ & $<0.0001^{\mathrm{b}}$ \\
\hline
\end{tabular}

Abbreviation: BMI, body mass index.

${ }^{a}$ Values are expressed as No. (\%) or mean \pm SD.

${ }^{\mathrm{b}}$ Statistically significant $\mathrm{P}<0.05$.

Iranian Azeri population. The genotypes and alleles distributions in the case and control groups are demonstrated in Table 2.

\section{Discussion}

We investigated the association of the AURKC gene rs58264281 polymorphism and idiopathic male infertility among 100 patients with azoospermia and/or oligospermia and 100 healthy controls with previous successful reproduction from the Iranian Azeri population. Our results indicated a significant correlation between the AURKC gene rs58264281 polymorphism and idiopathic male infertility. We suggest that A mutant allele can increase infertility risk in Iranian Azeri patients.

Our knowledge about the molecular mechanisms of male infertility is insignificant and more studies are required for the identification of the main cause of azoospermia or oligospermia (16). Hence, extensive studies have been conducted for the identification of the genetic causes of male infertility; however, the etiology of approximately $40 \%$ of all the cases of male infertility remains unknown, which is called idiopathic male infertility. Previous studies demonstrated that mutations and SNPs on spermatogenesis-related genes are the common genetic causes of male azoospermia or oligospermia $(17,18)$. The
AURKA gene is involved in the regulation of $\mathrm{G} 2$ to $\mathrm{M}$ phase transition during cell cycle (18). Several variants of the $A U$ $R K C$ gene have been identified to be associated with male infertility $(14,15)$.

In recent years, numerous studies have investigated the association of various mutations and SNPs in the AURKC gene with male infertility in various races and geographical areas. In a study by Khelifa et al., a heterozygous variant of the AURKC gene (c.436-2A>G) was identified in infertile men with macrozoospermia and non-megaloheaded spermatozoa (14). In another study by Khelifa et al., a novel nonsense mutation in the AURKC gene (p.Y248*) was reported in infertile men from European and North African populations (12). A study by Ghédir et al. reported that approximately $80 \%$ of infertile men with macrozoospermia were homozygous for a mutation on the AURKC gene (c.144delC) in the population of Tunisia (16). However, in a study by Larbi et al., no mutations on the AURKC gene were noted in Algerian men with infertility (19). These results demonstrated that the molecular analysis of the AURKC gene in infertile men is key for the efficient management of reproduction problems in men.

To our knowledge, our study is the first positive report on the significant correlation of the AURKC gene rs58264281 polymorphism and male infertility in the Iranian Azeri population. The discrepancies in the results of 
Behvarz Met al.

\begin{tabular}{|c|c|c|c|c|c|c|}
\hline $\begin{array}{l}\text { Gene } \\
\text { (polymorphism) }\end{array}$ & $\begin{array}{l}\text { Inheritance } \\
\text { Models }\end{array}$ & $\begin{array}{c}\text { Genotype and } \\
\text { Allele }\end{array}$ & Case $(\%)$ & Control (\%) & P-Value & OR $(95 \% \mathrm{CI})$ \\
\hline \multirow{11}{*}{$\begin{array}{l}\text { AURKC } \\
\text { (rs58264281) }\end{array}$} & \multirow{3}{*}{ Codominant } & CC & $83(83)$ & $98(98)$ & Ref & $\operatorname{Ref}=1$ \\
\hline & & $\mathrm{CA}$ & $12(12)$ & $2(2)$ & $0.0046^{\mathrm{a}}$ & $7.08(1.7-32.2)$ \\
\hline & & $\mathrm{AA}$ & $5(5)$ & $0(0)$ & $0.022^{\mathrm{a}}$ & $\begin{array}{l}\text { infinity (1.7- } \\
\text { infinity) }\end{array}$ \\
\hline & \multirow{2}{*}{ Dominant } & CC & $83(83)$ & $98(98)$ & Ref & $\operatorname{Ref}=1$ \\
\hline & & $\mathrm{CA}+\mathrm{AA}$ & $17(17)$ & $2(2)$ & $0.0004^{\mathrm{a}}$ & $10.04(2.37-44.5)$ \\
\hline & \multirow{2}{*}{ Recessive } & $\mathrm{AA}$ & $5(5)$ & $0(0)$ & Ref & $\operatorname{Ref}=1$ \\
\hline & & $\mathrm{CA}+\mathrm{CC}$ & $95(95)$ & $100(100)$ & 0.059 & $\begin{array}{l}\text { infinity (1.5 - } \\
\text { infinity) }\end{array}$ \\
\hline & \multirow{2}{*}{ Overdominant } & $\mathrm{CA}$ & $12(12)$ & $2(2)$ & Ref & $\operatorname{Ref}=1$ \\
\hline & & $\mathrm{CC}+\mathrm{AA}$ & $88(88)$ & $98(98)$ & $0.010^{\mathrm{a}}$ & $6.68(1.6-30.4)$ \\
\hline & \multirow{2}{*}{ Alleles } & C wild & $178(89)$ & $198(99)$ & Ref & $\operatorname{Ref}=1$ \\
\hline & & A mutant & $22(11)$ & $2(1)$ & $0.0001^{\mathrm{a}}$ & $12.2(3.2-53.1)$ \\
\hline
\end{tabular}

${ }^{\mathrm{z}}$ Abbreviations: OR, odds ratio; $\mathrm{CI}$, confidence interval.

${ }^{\text {a }}$ Statistically significant $\mathrm{P}<0.05$.

previous studies may be due to the interaction of other genes involved in male infertility. Moreover, differences in genetic background, geographical area, sample selection bias, sample size, environmental factors, ethnicity, and race are the possible could account for the contradiction in previous findings (20-22).

\subsection{Conclusion}

In sum, our study suggests that the AURKC gene rs58264281 polymorphism is significantly associated with male infertility risk in the Iranian Azeri population. However, due to the widely inconsistent results by different studies, we recommend further extensive studies among other populations, races, and ethnic groups with larger sample sizes.

\section{Footnotes}

Authors' Contribution: M.B performed the research; S.A.R and E.S.T designed the research study; M.B and S.A.R contributed to essential reagents or tools; E.S.T analyzed the data; M.B wrote the paper. All the authors have read and approved the manuscript.

Conflict of Interests: The authors declare that they have no conflicts of interest.

Ethical Approval: The present study was confirmed by the Ethics Committee of Islamic Azad University, North Tehran Branch, Tehran, Iran (code of ethics: IR.IAU.TNB.REC.1399.030).

Funding/Support: There was no funding/support.
Informed Consent: Informed consent was signed by the study participants

\section{References}

1. Agarwal A, Mulgund A, Hamada A, Chyatte MR. A unique view on male infertility around the globe. Reprod Biol Endocrinol. 2015;13:37. doi: 10.1186/s12958-015-0032-1. [PubMed: 25928197]. [PubMed Central: PMC4424520].

2. Takeda T, Iwatsuki S, Hamakawa T, Mizuno K, Kamiya H, Umemoto Y, et al. Chromosomal anomalies and sperm retrieval outcomes of patients with non-obstructive azoospermia: A case series. Andrology. 2017;5(3):473-6. doi: 10.1111/andr.12338. [PubMed: 28235252].

3. Soheilyfar S, Nikyar T, Fathi Maroufi N, Mohebi Chamkhorami F, Amini Z, Ahmadi M, et al. Association of IL-10, IL-18, and IL33 genetic polymorphisms with recurrent pregnancy loss risk in Iranian women. Gynecol Endocrinol. 2019;35(4):342-5. doi: 10.1080/09513590.2018.1528220. [PubMed: 30526181].

4. Nasirpour H, Azari Key Y, Kazemipur N, Majidpour M, Mahdavi S, Hajazimian S, et al. Association of Rubella, Cytomegalovirus, and Toxoplasma Infections with Recurrent Miscarriages in Bonab-Iran: A Case-Control Study. Gene Cell and Tissue. 2017;In Press(In Press). doi: 10.5812 /gct.60891.

5. Hajizadeh YS, Emami E, Nottagh M, Amini Z, Maroufi NF, Azimian $\mathrm{SH}$, et al. Effects of interleukin-1 receptor antagonist (IL-1Ra) gene 86 bp VNTR polymorphism on recurrent pregnancy loss: A case-control study. Horm Mol Biol Clin Investig. 2017;30(3). doi: 10.1515/hmbci-20170010. [PubMed: 28593919].

6. Isazadeh A, Hajazimian S, Rahmani SA, Mohammadoo-Khorasani M, Samanmanesh S, Karimkhanilouei S. The effects of Factor II (rs1799963) polymorphism on recurrent pregnancy loss in Iranian Azeri women. Italian Journal of Laboratory Medicine. 2017;13(1):37-40. doi: 10.1007/s13631-017-0145-y.

7. Isazadeh A, Hajazimian S, Rahmani SA, Mohammadoo-Khorasani M, Moghtaran N, Fathi Maroufi N. The Effect of Factor-XI (rs3756008) Polymorphism on Recurrent Pregnancy Loss in Iranian Azeri Women. Gene Cell and Tissue. 2016;4(1). doi:10.17795/gct-43717. 
8. Shiralizadeh J, Barmaki H, Haiaty S, Faridvand Y, Mostafazadeh M, Mokarizadeh $\mathrm{N}$, et al. The effects of high and low doses of folic acid on oxidation of protein levels during pregnancy: a randomized double-blind clinical trial. Horm Mol Biol Clin Investig. 2017;33(3). doi: 10.1515/hmbci-2017-0039. [PubMed: 28866652].

9. Dieterich K, Soto Rifo R, Faure AK, Hennebicq S, Ben Amar B, Zahi M, et al. Homozygous mutation of AURKC yields large-headed polyploid spermatozoa and causes male infertility. Nat Genet. 2007;39(5):661-5. doi: 10.1038/ng2027. [PubMed: 17435757].

10. Carmena M, Earnshaw WC. The cellular geography of aurora kinases. Nat Rev Mol Cell Biol. 2003;4(11):842-54. doi: 10.1038/nrm1245. [PubMed: 14625535].

11. Yan X, Cao L, Li Q, Wu Y, Zhang H, Saiyin H, et al. Aurora C is directly associated with Survivin and required for cytokinesis. Genes Cells. 2005;10(6):617-26. doi: 10.1111/j.1365-2443.2005.00863.x. [PubMed: 15938719].

12. Ben Khelifa M, Coutton C, Blum MG, Abada F, Harbuz R, Zouari R, et al. Identification of a new recurrent aurora kinase $C$ mutation in both European and African men with macrozoospermia. Hum Reprod. 2012;27(11):3337-46. doi: 10.1093/humrep/des296. [PubMed: 22888167].

13. Ounis L, Zoghmar A, Coutton C, Rouabah L, Hachemi M, Martinez D, et al. Mutations of the aurora kinase $C$ gene causing macrozoospermia are the most frequent genetic cause of male infertility in Algerian men. Asian J Androl. 2015;17(1):68-73. doi: 10.4103/1008-682X.136441. [PubMed: 25219909]. [PubMed Central: PMC4291881].

14. Ben Khelifa M, Zouari R, Harbuz R, Halouani L, Arnoult C, Lunardi J, et al. A new AURKC mutation causing macrozoospermia: implications for human spermatogenesis and clinical diagnosis. Mol Hum Reprod. 2011;17(12):762-8. doi: 10.1093/molehr/gar050. [PubMed: 21733974]. [PubMed Central: PMC3639514].

15. Dieterich K, Zouari R, Harbuz R, Vialard F, Martinez D, Bellayou H, et al. The Aurora Kinase C c.144delC mutation causes meiosis I arrest in men and is frequent in the North African population. Hum Mol Genet. 2009;18(7):1301-9. doi: 10.1093/hmg/ddp029. [PubMed: 19147683].
16. Ghedir H, Gribaa M, Mamai O, Ben Charfeddine I, Braham A, Amara A, et al. Macrozoospermia: screening for the homozygous c.144delC mutation in AURKC gene in infertile men and estimation of its heterozygosity frequency in the Tunisian population. J Assist Reprod Genet. 2015;32(11):1651-8. doi: 10.1007/s10815-015-0565-4. [PubMed: 26341096]. [PubMed Central: PMC4651955].

17. Cheetham GM, Knegtel RM, Coll JT, Renwick SB, Swenson L, Weber P, et al. Crystal structure of aurora-2, an oncogenic serine/threonine kinase.J Biol Chem. 2002;277(45):42419-22. doi:10.1074/jbc.C200426200. [PubMed: 12237287].

18. Reijo R, Lee TY, Salo P, Alagappan R, Brown LG, Rosenberg M, et al. Diverse spermatogenic defects in humans caused by $\mathrm{Y}$ chromosome deletions encompassing a novel RNA-binding protein gene. Nat Genet.1995;10(4):383-93. doi:10.1038/ng0895-383. [PubMed: 7670487].

19. Mohamed Larbi R, Djalila C, Noureddine A, Dalila S. Screening for the Homozygous C.144delc Mutation in Aurkc Gene in Algerian Infertile Men. Asian J Pharm Clin Res. 2018;11(2):161. doi: 10.22159/ajpcr.2018.v11i2.22783.

20. Isazadeh A, Haj Azimian S, Tariverdi N, Rahmani SA, Esmaeili M, Karimkhanilouei S, et al. Effects of coagulation factor XIII (Val34Leu) polymorphism on recurrent pregnancy loss in Iranian Azeri women. LaboratoriumsMedizin. 2017;41(2). doi: 10.1515/labmed-2017-0012.

21. Fathi Maroufi N, Gholampour Matin M, Ghanbari N, Khorrami A, Amini Z, Haj Azimian S, et al. Influence of single nucleotide polymorphism in IL-27 and IL-33 genes on breast cancer. Br J Biomed Sci. 2019;76(2):89-91. doi: 10.1080/09674845.2018.1545554. [PubMed: 30406733].

22. Fathi Maroufi N, Aghayi E, Garshasbi H, Gholampour Matin M, Babazadeh Bedoustani A, Firouzi Amoudizaj F, et al. Association of rs1946518 C/A Polymorphism in Promoter Region of Interleukin 18 Gene and Breast Cancer Risk in Iranian Women: A Casecontrol Study. Iran J Allergy Asthma Immunol. 2019;18(6):671-8. doi: 10.18502/ijaai.v18i6.2180. [PubMed: 32245311]. 